\title{
Nonbactericidal Antibodies against Neisseria gonorrhoeae: Evaluation of Their Blocking Effect on Bactericidal Antibodies Directed against Outer Membrane Antigens
}

\author{
By M. VIRJI* AND J. E. HECKELS \\ Department of Microbiology, Southampton University Medical School, Southampton General \\ Hospital, Tremona Road, Southampton SO9 4XY, UK
}

(Received 7 March 1988)

\begin{abstract}
Nonbactericidal monoclonal antibodies (MAbs) directed against gonococcal surface antigens were examined for their effect on complement-mediated bactericidal killing by other MAbs and normal human serum. One MAb, SM73, directed against the H.8 antigen activated complement only moderately well and had little influence on bactericidal antibodies. Two antibodies directed against an epitope on protein III had very different effects. Antibody SM51 activated complement poorly and had no effect on bactericidal killing, whereas antibody SM50, although itself nonbactericidal, activated complement and blocked the bactericidal effect of other antibodies. The extent of the blocking ability of MAb SM50 was studied using MAbs of different specificities as well as polyclonal antisera raised aginst gonococcal surface antigens. Antibody SM50 blocked IgG MAbs of all specificities, but several MAbs of the IgM class retained their bactericidal effect. Each of these IgM MAbs reacted with lipopolysaccharide, but with different epitopes.
\end{abstract}

\section{INTRODUCTION}

Complement-mediated killing of gonococci is an important defence mechanism especially in the prevention of disseminated infections (Rice \& Goldenberg, 1981). Many strains which cause disseminated gonococcal infections are resistant to the bactericidal action of normal human serum (NHS) (Schoolnik et al., 1976). Many serum-resistant organisms are, however, rendered sensitive to complement-mediated bactericidal killing by the presence of antibodies directed against specific outer membrane (OM) antigens (Joiner et al., 1983; Virji \& Heckels, 1985; Virji et al., 1986, 1987 $a, b)$. Therefore, one important feature of any potential gonococcal vaccine would be to induce effective bactericidal antibodies. In studies designed to identify potential candidate antigens for vaccination, we raised a panel of monoclonal antibodies (MAbs) directed against distinct epitopes on a variety of different $O M$ antigens and examined their efficacy in in vitro models of biological defence mechanisms (Virji \& Heckels, 1985; Virji et al., 1986, 1987 a, b). These studies have revealed the importance of the particular location of epitopes on a single antigen, since MAbs recognizing distinct epitopes may exhibit markedly different properties in biological assays. Many of the antigens studied possessed epitopes which stimulated complement-fixing antibodies which were bactericidal or nonbactericidal in nature (Virji \& Heckels, 1985; Virji et al., 1986). This was particularly true in the case of protein III (P.III) (Virji et al., 1987a), which is highly conserved in $N$. gonorrhoeae (Lytton \& Blake, 1986) and, therefore, potentially an important candidate for vaccine studies. However, other workers have reported

\footnotetext{
Abbreviations: CFT, complement fixation test; MAb, monoclonal antibody; NHS, normal human serum; OM, outer membrane.
} 
that antibodies directed against this protein are not only nonbactericidal, but also block the bactericidal action of antibodies directed against other surface antigens (Joiner et al., 1985a, $b$; Rice et al., 1986).

The ability of P.III to elicit such blocking antibodies appears to be a major obstacle to its consideration as a candidate vaccine antigen. However, previous studies from this laboratory used MAbs to identify three distinct immunogenic regions on P.III, only one of which elicited nonbactericidal antibodies, the other two inducing an effective bactericidal response (Virji $e t$ $a l ., 1987 a$ ). In the present report we have used nonbactericidal MAbs aginst P.III as well as other proteins in order to examine their potential blocking effect. We have also used bactericidal MAbs directed against several different surface antigens in order to identify the best candidate antigen/s for eliciting bactericidal antibodies which might remain effective in the presence of preexisting blocking antibodies.

\section{METHODS}

Bacteria. A piliated $\left(\mathrm{Pil}^{+}\right)$variant of strain P9 (P9-2) lacking protein II (P.II) was used in the majority of the experiments; variant P9-17 (Pil $\left.{ }^{+}, \mathrm{P} . \mathrm{IIb}^{+}\right)$was used in conjunction with the anti-P.IIb MAb, viz. SM40. The strain P9 expresses a major OM protein of type P.IB and is serum resistant in the presence of $10 \%(\mathrm{v} / \mathrm{v})$ NHS. Another serum-resistant strain SU93, expressing P.IA, and serum-sensitive strains SU62, SU87, and SU88 were also used. These strains were obtained from local sources as described by Zak et al. (1984).

$O M$ antigens. OM vesicles were prepared by lithium acetate extraction of gonococci (Heckels, 1977).

$M A b s$. Details of the immunizations, fusions and cloning procedures used for obtaining MAbs directed against a variety of $\mathrm{OM}$ antigens, including pili, P.IB, P.IA, P.IIb and P.III, have been described previously (Virji \& Heckels, 1986; Virji et al., 1983, 1987 a, b; Fletcher $e$ t al., 1986). In addition, other MAbs arising from these fusions which were directed against lipopolysaccharide (LPS), the H.8 antigen and the $45 \mathrm{kDa}$ OM protein (Virji et al., 1985) have also been used. Reactivities of the MAbs was determined by dot-blot screening of a panel of 50 gonococcal and 20 meningococcal strains as described previously (Virji et al., 1987a). Some properties of these MAbs are summarized in Table 1 .

Polyclonal antisera. Antisera were raised either in mice or in rabbits by repeated immunization with OM complex from strain P9 (Diaz \& Heckels, 1982) or purified P.I (unpublished data, J. E. Heckels and M. Virji).

Complement source. Fresh blood from donors with no known history of gonorrhoea was allowed to clot at room temperature and centrifuged at $1500 \mathrm{~g}$ for $10 \mathrm{~min}$. Samples were immediately frozen at $-70^{\circ} \mathrm{C}$ until required. In most experiments a single source of fresh NHS was used as the source of complement and was present at $10 \%(\mathrm{v} / \mathrm{v})$ concentration. In some experiments the effects of different sources of complement from two individuals of different blood groups were examined.

Bactericidal effect of $M A$ Abs. The bactericidal action of the antibodies was determined by incubating gonococci ( 1000 c.f.u. in $0 \cdot 1 \mathrm{ml}$ ) in the presence of different dilutions of antibody and complement (as described above) for $1 \mathrm{~h}$ at $37^{\circ} \mathrm{C}$ (Virji \& Heckels, 1985). Samples were plated out on agar for estimation of surviving c.f.u. and each estimation was done in triplicate. No significant effect of antibody-mediated agglutination was apparent in the estimation of c.f.u. at the dilutions of MAbs or antisera used. Antibodies which were nonbactericidal in these tests were reexamined by precoating gonococci at room temperature for $10 \mathrm{~min}$ in the presence of $1: 20$ dilutions of ascites fluid prior to incubation with complement at $37^{\circ} \mathrm{C}$ for $1 \mathrm{~h}$.

Blocking of the bactericidal effect was studied by preincubating bacteria for $10 \mathrm{~min}$ at room temperature with nonbactericidal MAbs prior to exposure to bactericidal antibodies and complement. The mixture was then incubated for $1 \mathrm{~h}$ at $37^{\circ} \mathrm{C}$ and the number of surviving bacteria (c.f.u.) was determined as described above. In some cases, the effect of simultaneous incubation $\left(1 \mathrm{~h}, 37^{\circ} \mathrm{C}\right)$ of the nonbactericidal and bactericidal MAbs was also examined.

Complement utilization. Relative amounts of complement utilization by different antibodies were determined in a complement fixation test (CFT). Sensitized sheep erythrocytes (SSE) were prepared by incubation $\left(1 \mathrm{~h}, 37^{\circ} \mathrm{C}\right)$ with rabbit anti-sheep haemolysin (Gibco) present at 1:500 dilution in CFT buffer (Gibco). For analysis of complement activation, OM preparations from strain P9 $\left(10 \mu \mathrm{g}\right.$ protein $\left.\mathrm{ml}^{-1}\right)$ were first mixed with serial dilutions of MAbs in Microwell plates (V-well, Gibco) before the addition of fresh NHS. After $45 \mathrm{~min}$ at $37^{\circ} \mathrm{C}$, $25 \mu \mathrm{l}$ of $2 \%(\mathrm{v} / \mathrm{v}) \mathrm{SSE}$ was added in a final volume of $100 \mu \mathrm{l}$; the incubation was continued for a further $45 \mathrm{~min}$. The plates were then centrifuged briefly in an MSE GF- 8 centrifuge. A sample $(50 \mu \mathrm{l})$ of the supernatant fraction from each well was transferred to a microtitre plate (flat-bottomed well, Sterilin), diluted $1: 2$ and the $A_{405}$ was measured in a Titretek Twinreader (Flow Laboratories). In the absence of added antibody all the complement was available for lysis of SSE, producing the maximum absorbance. Conversely when NHS was replaced with serum in which complement had been inactivated, no lysis of SSE occurred giving a basal value of absorbance. These parameters were used to define the $0-100 \%$ levels of complement utilization by antibody-antigen complexes. 
Table 1. Properties of MAbs used in investigations of bactericidal blocking

\begin{tabular}{|c|c|c|c|c|}
\hline Antibody & $\begin{array}{c}\text { Target } \\
\text { antigen }\end{array}$ & Isotype & $\begin{array}{l}\text { Bactericidal } \\
\text { effect* }\end{array}$ & Reference $\dagger$ \\
\hline SM20 & P.IB & $\gamma 2 \mathrm{a}$ & w & $a$ \\
\hline SM23 & P.IB & $\mu$ & w & $a$ \\
\hline SM24 & P.IB & $\gamma 2 \mathrm{a}$ & + & $a$ \\
\hline SM101 & P.IA & $\gamma 2 \mathrm{~b}$ & + & $b$ \\
\hline SM40 & P.IIb & $\gamma 3$ & + & $c$ \\
\hline SM50 & P.III & $\gamma 2 \mathrm{a}$ & - & $d$ \\
\hline SM51 & P.III & $\gamma 1$ & - & $d$ \\
\hline SM52 & P.III & $\gamma 1$ & + & $d$ \\
\hline SM54 & P.III & $\gamma 2 b$ & + & $d$ \\
\hline SM55 & P.III & $\gamma 2 a$ & + & $d$ \\
\hline SM70 & H.8 & $\gamma 2 \mathrm{~b}$ & w & $e$ \\
\hline SM72 & H. 8 & $\gamma 3$ & $\mathbf{w}$ & $e$ \\
\hline SM73 & H. 8 & $\gamma 3$ & - & $e$ \\
\hline SM81 & LPS & $\gamma 2 \mathrm{a}$ & + & $e$ \\
\hline SM82 & LPS & $\mu$ & + & $e$ \\
\hline SM180 & LPS & $\mu$ & + & $e$ \\
\hline SM187 & LPS & $\mu$ & + & $e$ \\
\hline SM188 & LPS & $\gamma 3$ & + & $e$ \\
\hline SM189 & LPS & $\mu$ & + & $e$ \\
\hline SM90 & $45 \mathrm{kDa}$ protein & $\gamma 2 \mathrm{a}$ & w & $e$ \\
\hline SM1 & Pili & $\gamma 2 \mathrm{a}$ & $\mathbf{w}$ & $e$ \\
\hline SM3 & Pili & $\gamma 1$ & + & $f$ \\
\hline SM4 & Pili & $\mu$ & + & $e$ \\
\hline SM11 & Pili & $\mu$ & + & $e$ \\
\hline SM13 & Pili & $\gamma 2 \mathrm{a}$ & w & $e$ \\
\hline
\end{tabular}

* w, Weak bactericidal effect only obtained when gonococci were preincubated with high concentrations of MAbs (1:20 dilution of ascites fluid) as described in Methods, before addition of complement.

$\dagger($ a $)$ Virji et al. (1986); (b) Virji et al. (1987b); (c) Heckels \& Virji (1986); (d) Virji et al. (1987a); (e) This paper; (f) Virji \& Heckels (1985).

\section{RESULTS}

\section{Identification of nonbactericidal antibodies}

Studies with anti-P.IB MAbs have shown that whereas SM24 $(\gamma 2 \mathrm{a})$ was bactericidal under all conditions, with titres exceeding $1: 20000$ for strain P9, antibodies SM20 $(\gamma 2 \mathrm{a})$ and SM23 $(\mu)$ were nonbactericidal, except when gonococci were precoated with high concentrations ( $1: 20$ dilution) of the ascites fluids containing these MAbs before addition of complement (Virji et al., 1986). These differences were not related to the amount of immunoglobulin in the ascites fluids which only varied between 1.5 and $6 \mathrm{mg} \mathrm{ml}^{-1}$. As shown in Table 1 other MAbs were found to be weakly bactericidal under similar conditions. However, three MAbs were identified which were totally nonbactericidal under all conditions. Two of these MAbs SM50 $(\gamma 2 \mathrm{a})$ and SM51 $(\gamma 1)$, were directed against a single epitope or very closely positioned epitopes on P.III (Virji et al., 1987a); the third MAb SM73 $(\gamma 3)$ was directed against the H.8 antigen.

\section{Potential blocking effect of nonbactericidal antibodies}

(a) Monoclonal antibodies. Variant P9-2, normally resistant to $10 \%$ NHS, is rendered sensitive by the additional presence of anti-OM MAbs (Virji et al., 1986, 1987a). The bactericidal killing by two normally effective MAbs (SM24, anti-P.IB; SM188, anti-LPS) was examined in the presence of the three nonbactericidal MAbs, each present at 1:20 dilution. Results are shown in Fig. 1(a). Two antibodies were able to block gonococcal killing; SM50 was the most effective, whereas SM73 had some effect in one case. In contrast SM51 was totally ineffective. The efficiency of blocking of the bactericidal activity of SM24 by SM50 was demonstrated by increasing the dilutions of the blocking antibody and occurred at low concentrations of SM50 (Fig. 1b). In these experiments bacteria were first precoated with SM50 as described in 


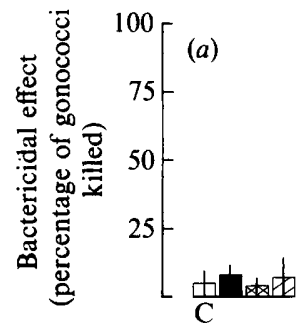

Bactericidal MAb ... None

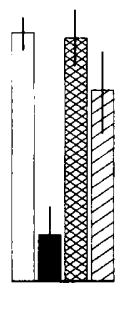

SM24

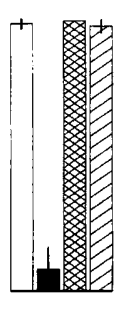

SM188

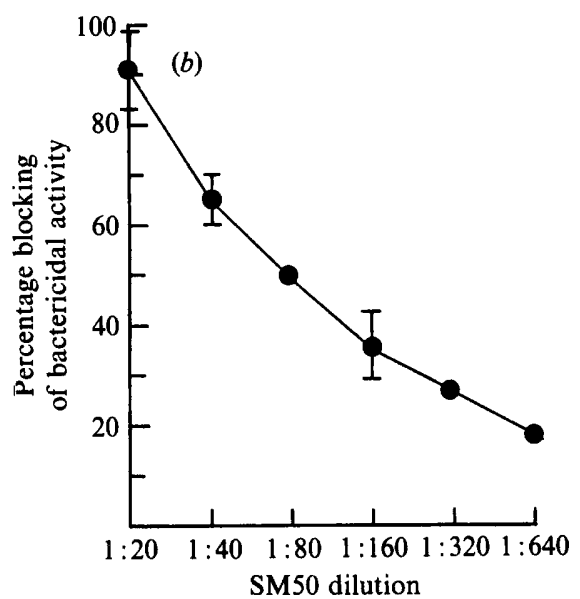

Fig. 1. (a) Blocking of bactericidal killing. Bactericidal MAbs SM24 (anti-P.IB) and SM188 (anti-LPS) were tested for their ability to kill the gonococcal variant P9-2 after preincubation for $10 \mathrm{~min}$ at room temperature with nonbactericidal anti-P.III MAbs SM50 (ם), SM51 (囚) or anti-H.8 Ab SM73 (घ), present at a 1:20 dilution of ascites fluid. Controls $(\square)$ contained the bactericidal MAbs alone, which were present at a 1:40 dilution of ascites fluid. C, complement control in the absence of added MAb. Means of values from two experiments are plotted and the ranges are shown. $(b)$ Efficiency of MAb SM50 in blocking bactericidal anti-P.IB MAb SM24. Variant P9-2 was preincubated (10 min, room temperature) with serial twofold dilutions of MAb SM50; MAb SM24 was then added at a dilution of $1: 100$. Other details were as in the text. Percentage blocking of bactericidal action of MAb SM24 was determined as $100[1$ - (percentage killing in the presence of MAb SM50/percentage killing in the absence of MAb SM50)]. Ranges of values at some dilutions are from two experiments.

Table 2. Sensitivity of gonococcal strains to NHS and blocking of the bactericidal effect by non-bactericidal MAbs

Effect of nonbactericidal antibodies on serum killing of three gonococcal strains was studied by preincubation in the presence of $1: 20$ dilution of ascites fluid containing MAb. Mean values of three estimations from one representative experiment are shown. Probability values were obtained by Student's $t$-test.

\begin{tabular}{lrrrr} 
& \multicolumn{4}{c}{$\begin{array}{c}\text { Percentage of gonococci killed in the presence of NHS } \\
\text { after preincubation with indicated MAb }\end{array}$} \\
Strain & MAb . . None & SM50* & SM51 & SM73* $^{*}$ \\
SU62 & 100 & $37(<0 \cdot 001)$ & 100 & 100 \\
SU87 & 37 & $0(<0 \cdot 02)$ & 39 & $18(<0 \cdot 1)$ \\
SU88 & 50 & $22(<0 \cdot 1)$ & ND & ND
\end{tabular}

ND, Not done.

* Values indicated in parentheses are the $P$ values compared to the control preincubated in the absence of MAb.

Methods. Indeed the bactericidal activity of SM24 was significantly reduced even when SM50 was added and incubated simultaneously with SM24 (data not shown).

(b) $N H S$. Several gonococcal strains were tested for their serum sensitivity using fresh sera from two donors. The pattern of serum sensitivity of these strains was remarkably similar with both sera, thus eliminating the possibility of specific variations between these sera. When the nonbactericidal antibodies were present in addition to $10 \%$ NHS, significant inhibition in killing of the serum-sensitive strains was observed with MAb SM50, whereas the other two MAbs were largely ineffective (Table 2). 


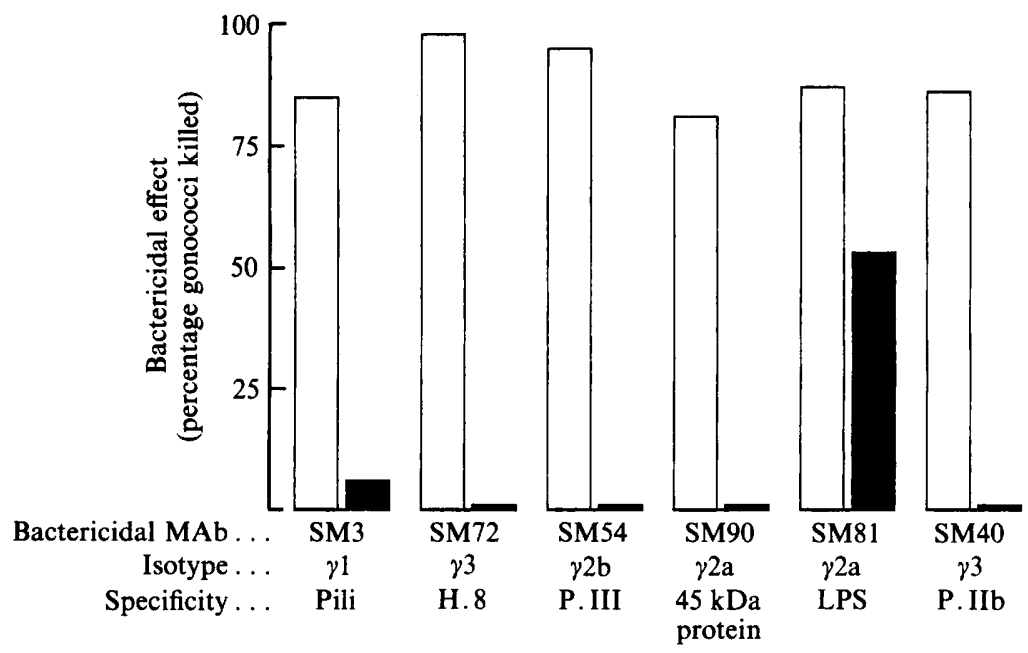

Fig. 2. Blocking of bactericidal IgG MAbs by MAb SM50. Several MAbs of different antigenic specificities were used at high concentrations to obtain $100 \%$ killing of gonococci (dilutions ranged from $1: 20$ to $1: 100$ of the ascites fluids). Gonococci were first preincubated for $10 \mathrm{~min}$ at room temperature in either the absence ( $\square$ ) or the presence ( $\square$ ) of MAb SM50 (1:20 dilution of ascites fluid); bactericidal MAbs and complement were then added and further incubated at $37^{\circ} \mathrm{C}$ for $1 \mathrm{~h}$. Variant P9-2 (P.II $)$ was used in conjunction with all MAbs with the exception of MAb SM40. In the latter case, the P.IIb ${ }^{+}$variant P9-17 was used. Results are from a typical experiment. SD values of triplicate estimations were less than $\pm 20 \%$.

\section{Distinction between competitive binding and blocking of the bactericidal effect by MAb SM50}

One possible explanation of the blocking effect of MAb SM50 was that its binding sterically inhibited binding of the bactericidal antibodies. As previously reported (Virji et al., 1987b), in competitive radioimmunoassays, inhibition in binding of the anti-P.IA MAb SM101 in the presence of the MAb SM50 only occurred when the latter MAb was present at 80-fold greater concentration. However, in the present study, the bactericidal activity of SM101 was significantly inhibited in the presence of much lower concentrations of SM50. At equivalent dilutions of the two MAbs, the killing of the P.IA-expressing strain SU93 was reduced by $65 \%$ compared with controls using SM101 alone (which killed $100 \%$ of the gonococci). Thus, blocking of immunoglobulin binding and of the bactericidal effect occurred at very different concentrations of SM50, showing that the blocking effect was not due to inhibition of binding of the bactericidal antibody.

\section{Effect of MAb SM50 on the bactericidal effect of MAbs directed against OM antigens}

MAbs of the IgG class directed against six different OM antigens other than P.I were investigated in bactericidal assays. When present, MAb SM50 was preincubated with gonococci and the bactericidal antibody was then added followed by $10 \%$ NHS as the source of complement. In Fig. 2, a representative example from MAbs of each specificity has been plotted. In each case SM50 blocked the bactericidal effect of the IgG MAb tested.

The investigations with MAbs of the IgM class were confined mainly to those against LPS since this antigen readily stimulates an IgM response. In addition, two anti-pilus MAbs of the IgM class which were available were also used. The effect of the weakly bactericidal anti-pilus MAbs was inhibited considerably by SM50. In contrast, the bactericidal effect of the anti-LPS MAbs was not readily inhibited. Two antibodies, SM180 and SM187, were investigated further and blocking of their bactericidal activity by SM50 was only demonstrated when its concentration exceeded those of the two bactericidal antibodies by 250 - and 50 -fold, respectively (Table 3). 
Table 3. Bactericidal effect of IgM MAbs after pretreatment of gonococci with MAb SM50

Effect of MAb SM50 on bactericidal killing was investigated using variant P9-2 and $10 \%(\mathrm{v} / \mathrm{v})$ NHS. Gonococci were preincubated for $10 \mathrm{~min}$ at room temperature with SM50 before addition of the IgM MAbs. SM50 was present throughout at 1:20 dilution of ascites fluid. IgG MAbs SM3 and SM188 were included as controls. Estimations of surviving c.f.u. were done in triplicate and the mean values were used in calculating the percentage killing. SD values were less than $\pm 20 \%$.

\begin{tabular}{lcclcr} 
& & & \multicolumn{2}{c}{$\begin{array}{c}\text { Percentage of gonococci } \\
\text { killed after } \\
\text { preincubation with } \\
\text { MAb SM50 }\end{array}$} \\
MAb & Specificity & Isotype & Dilution & $\overbrace{- \text { SM50 }}+$ SM50 \\
SM4 & Pili & $\mu$ & $1: 40$ & 98 & 0 \\
SM11 & Pili & $\mu$ & $1: 40$ & 80 & 7 \\
SM3 & Pili & $\gamma 1$ & $1: 40$ & 69 & 0 \\
SM82 & LPS & $\mu$ & $1: 200$ & 100 & 100 \\
SM189 & LPS & $\mu$ & $1: 200$ & 100 & 100 \\
SM180 & LPS & $\mu$ & $1: 200$ & 100 & 100 \\
& & & $1: 1000$ & 100 & 97 \\
SM187 & LPS & & $1: 5000$ & 100 & 70 \\
& & $\mu$ & $1: 10000$ & 100 & 51 \\
SM188 & LPS & $\gamma 3$ & $1: 200$ & 100 & 99 \\
& & & $1: 1000$ & 100 & 59 \\
& & & $1: 10000$ & 77 & 16 \\
& & & & 96 & 16
\end{tabular}

Table 4. Effect of preincubation with MAb SM50 on the bactericidal effect of polyclonal sera

Experimental details and SD values were as in Table 3.

\begin{tabular}{clcr} 
& Dilution & \multicolumn{2}{c}{$\begin{array}{c}\text { Percentage of gonococci } \\
\text { killed after } \\
\text { preincubation with } \\
\text { MAb SM50 }\end{array}$} \\
Antiserum & $\overbrace{\text { of sera }}$ & SM50 & + SM50 \\
Mouse anti-P9 OM & $1: 100$ & 100 & 100 \\
Rabbit anti-P9 OM & $1: 1000$ & 100 & 74 \\
Rabbit anti-P.I & $1: 100$ & 100 & 100 \\
& $1: 1000$ & 100 & 42 \\
$1: 200$ & 100 & 23 \\
$1: 1000$ & 79 & 4
\end{tabular}

The difference in the inhibition of the IgM and the IgG MAbs was not due to the difference in their specific titre. This was verified by ELISA using OM antigen from strain P9: MAb SM188 $(\gamma 3)$ gave consistently a higher titre compared with MAb SM180 $(\mu)$. Dot-blotting analysis with 50 gonococcal strains and 20 meningococcal strains showed that MAbs SM82 and SM180 reacted with all gonococci and meningococci. The rest of the anti-LPS MAbs exhibited different patterns of reactivity against the gonococcal strains, whilst each recognizing a large number of strains, suggesting that they must be directed against widely distributed but distinct epitopes.

\section{Blocking of polyclonal antisera}

In experiments similar to those described above, the effect of MAb SM50 on polyclonal antisera reactive with multiple $\mathrm{OM}$ antigens as well as a monospecific antiserum reactive with a single antigen (P.I) was investigated (Table 4). Blocking of the bactericidal activity of the antiP.I antiserum was readily observed, but MAb SM50 had relatively less effect on the two different anti-OM antisera. Western blotting and ELISA showed that the polyclonal anti-OM antisera contained antibodies directed against both LPS and the major OM proteins, P.I and P.III (data not shown). 


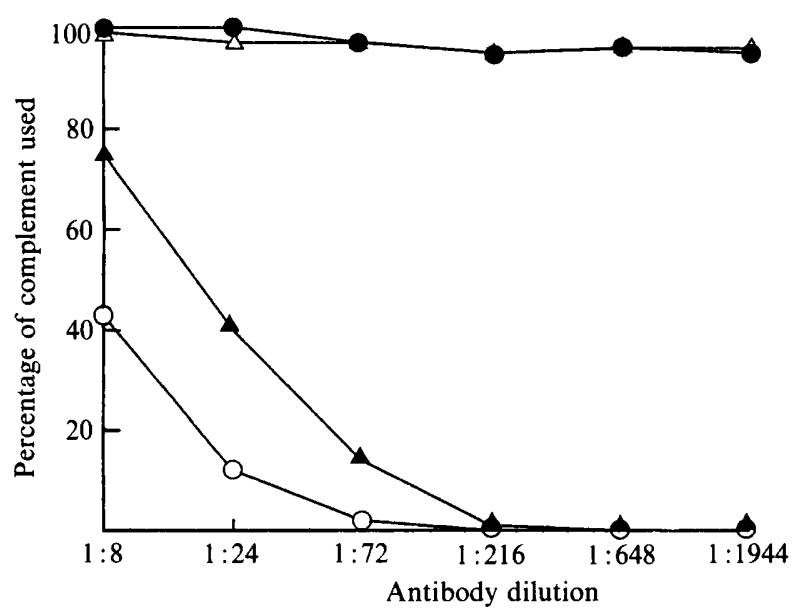

Fig. 3. Complement utilization by MAbs. A CFT was used to determine the relative amounts of complement used by anti-P.III MAbs. Serial threefold dilutions of ascites fluid containing the MAbs SM50 ( $)$, SM51 (O), SM52 ( $\Delta)$, and SM55 $(\triangle)$ were incubated in the presence of P9 OM and $1.5 \%$ $(v / v)$ NHS. Experimental details and treatment of the data are described in Methods.

\section{Complement utilization}

In a CFT, complement utilization by the nonbactericidal MAbs SM50 $(\gamma 2 \mathrm{a})$ and SM51 $(\gamma 1)$ were compared with utilization by two bactericidal MAbs, SM52 $(\gamma 1)$ and SM55 $(\gamma 2 \mathrm{a})$. These MAbs were matched in isotype and specificity: all reacted with P.III, but MAbs SM52 and SM55 recognized distinct epitopes (Virji et al., 1987a). Regardless of whether or not they were bactericidal, the MAbs of the $\gamma 2 \mathrm{a}$ isotype were much more effective in complement utilization compared with those of the $\gamma 1$ isotype (Fig. 3). Other experiments showed that although complement fixing, MAb SM73 $(\gamma 3)$ was much less effective than MAb SM50 in this test (data not shown).

\section{DISCUSSION}

One of the principal requirements of a potential vaccine directed against $N$. gonorrhoeae would be to induce effective bactericidal antibodies especially against those strains able to cause disseminated infections. Such strains remain resistant to the bactericidal activity of NHS even after laboratory subculture (Schoolnik et al., 1976). The studies in the present report are concerned with problems of overcoming such stable resistance. The mechanisms of resistance are unclear, although a number of $\mathrm{OM}$ antigens have been associated with conferring this property on the bacteria that possess them (reviewed by Britigan et al., 1985).

Recently, McShan et al. (1987) have reported that a $29 \mathrm{kDa}$ protein confers resistance to genetically transformed mutants by binding antibodies which block the bactericidal effect of NHS. Similar blocking by antibodies directed against protein III has been studied by several workers. Rice et al. (1986) showed that blocking antibodies present in some NHS and some convalescent sera were directed against P.III. However, a MAb against P.III (MAb 2E6) only marginally blocked the bactericidal effect of another MAb directed against P.I (Joiner et al., 1985a). The blocking appeared to be primarily due to the inhibition of binding of the bactericidal antibody since equivalent inhibition of binding was also demonstrated.

The reported differences in the blocking effect of antibodies directed against the highly conserved P.III may be due to differences in the epitopes recognized. Our studies with panels of MAbs have shown the presence of several immunogenic regions on P.III, some of which induced effective bactericidal antibodies whereas one elicited nonbactericidal antibodies (Virji 
et al., 1987a). In the present study one of these nonbactericidal antibodies (MAb SM50, $\gamma 2 \mathrm{a}$ ) blocked complement-mediated killing by MAbs directed against several different OM antigens. One possible explanation for the blocking effect, namely that binding of the first antibody may result in direct steric hindrance or a change to the antigenic site of another MAb against the same or a closely associated antigen, can be excluded in this case since SM50 has been shown by competitive radioimmunoassay not to inhibit binding of several other P.III MAbs or of MAb SM101 directed against P.IA (Virji et al., 1987a,b). Therefore, SM50 is unlike the MAb 2E6 both in its mode of action and magnitude of blocking. It should be noted that blocking by SM50 is not related to the number of binding sites on the OM since previous studies have shown that more anti-P.I MAbs bind to OM than anti-P.III MAbs (Virji et al., 1987a).

SM50 fixed complement efficiently in a CFT which was comparable to MAb SM55, a bactericidal antibody directed against a different epitope on P.III. The mechanism of bactericidal blocking by SM50 seems to be exclusively connected to its ability to fix complement, since the second nonbactericidal antibody directed against the same or closely positioned epitope (SM51, $\gamma 1$ ) fixed considerably less complement and did not block killing. Although MAbs of the $\gamma 1$ isotype vary in their ability to fix complement (Neuberger \& Rajewsky, 1981), another MAb of the $\gamma 1$ isotype, SM52, also exhibited a relatively low level of complement utilization. However, despite this low efficiency of complement utilization, SM52 is bactericidal. These observations suggest that as with other antigens (Virji et al., 1986), it is the location of the epitope on P.III that is of prime importance in complement bactericidal activity.

Joiner et al. (1985b) have suggested that antibodies binding to 'nonbactericidal' epitopes can divert the complement components away from fixation at sites which may bring about killing. It appears very likely that SM50 is able to block killing in this manner since it blocked the bactericidal activity of MAbs of different specificities of the IgG class independently of the proximity of their binding on the gonococcal surface. However, when several MAbs of the IgM class were examined, the blocking of bactericidal killing was much less evident. Thus IgM antibodies, with their greater potential for complement activation, seem to be able to compete with the blocking antibody in complement fixation. Moreover, the site of complement activation also seems to be important since all IgM MAbs against LPS retained bactericidal activity unlike anti-pilus MAbs which were readily blocked.

Blocking by SM50 of the bactericidal effect of several polyclonal sera yields further support to the importance of anti-LPS antibodies, in that antiserum against purified P.I (free from LPS) was more effectively blocked compared with that against the OM complex which contained anti-LPS antibodies. This may also be related to the presence of antibodies of the IgM class since LPS readily induces an IgM response in most animals. Finally, MAb SM50 also proved to be effective in blocking the effect of NHS on normally serum-sensitive strains, showing that they may also be rendered serum-resistant in the presence of anti-P.III antibodies.

Although P.III has been the principal subject of this study, we investigated MAbs of several specificities to identify other antigens against which blocking antibodies might be elicited. Only one other MAb, SM73, directed against the H.8 antigen, was truly non-bactericidal and blocking. Initial studies with MAbs and NHS showed that, although MAb SM73 blocked bactericidal killing, it was far less effective compared with MAb SM50. The reason for this may be its relative inefficiency in complement activation as demonstrated in CFT. It is likely that other more effective complement-fixing antibodies directed against the SM73-epitope may prove to be as potent in their effect as SM50. Further studies to verify this would require the use of isotype-switch variants exhibiting altered complement-fixing abilities (Kaminski et al., 1986).

The studies described above demonstrate the complexity of the interactions involved in bactericidal killing of gonococci by both normal and immune serum. Nevertheless they suggest that, although a conserved antigen such as P.III may naturally induce blocking antibodies, a detailed understanding of its role in killing may reveal the presence of epitopes which represent effective targets. The remaining problem is to discover how to selectively induce an immune response against these target epitopes. 
This work was supported by an MRC project grant.

\section{REFERENCES}

Britigan B. E., Cohen, M. S. \& Sparling, P. F. (1985). Gonococcal infection: a model of molecular pathogenesis. New England Journal of Medicine 312 , 1683-1694.

Diaz, J.-L. \& Heckels, J. E. (1982). Antigenic variation of outer membrane protein II in colonial variants of Neisseria gonorrhoeae P9. Journal of General Microbiology 128, 585-591.

Fletcher, J. N., ZaK, K., VIRJI, M. \& HeCKels, J. E. (1986). Monoclonal antibodies to gonococcal outer membrane protein $\mathrm{I}$ : location of a conserved epitope on protein I.B. Journal of General Microbiology 132, 1611-1620.

HeCkels, J. E. (1977). The surface properties of Neisseria gonorrhoeae: isolation of the major components of the outer membrane. Journal of General Microbiology 99, 333-341.

HeCKELS, J. E. \& VIRJI, M. (1986). Antigenic variation of gonococcal surface proteins: effect on virulence. In Protein-Carbohydrate Interactions in Biological Systems, pp. 89-93. Edited by D. L. Lark. London: Academic Press.

JoINER, K. A., WARren, K. A., Brown, E. J., Swanson, J. \& Frank, M. M. (1983). Studies on the mechanism of bacterial resistance to complementmediated killing. IV. C5b-9 forms higher molecular weight complexes with bacterial outer membrane constituents on serum resistant but not on serum sensitive Neisseria gonorrhoeae. Journal of Immuno$\log y$ 131, 1443-1451.

JoINER, K. A., WARREN, K. A., TAM, M. \& FranK, M. M. (1985a). Monoclonal antibodies directed against gonococcal protein I vary in bactericidal activity. Journal of Immunology 134, 3411-3419.

Joiner, K. A., Scales, R., Warren, K. A., Frank, M. M. \& RICE, P. A. $(1985 b)$. Mechanism of action of blocking Immunoglobulin G for Neisseria gonorrhoeae. Journal of Clinical Investigation 76, 17651772 .

Kaminski, M. S., Kitamura, K., Maloney, D. G., CAMPBELl, M. J. \& LeVY, R. (1985). Importance of antibody isotype in monoclonal anti-idiotype therapy of a murine B cell lymphoma. A study of hybridoma class switch variants. Journal of Immuno$\log y$ 136, 1123-1130.

LyTTON, E. J. \& BLAKE, M. S. (1986). Isolation and partial characterisation of the reduction-modifiable protein of Neisseria gonorrhoeae. Journal of Experimental Medicine 164, 1749-1759.

MCShan, W. M., Williams, R. P. \& Hull, R. A. (1987). A recombinant molecule from a disseminating strain of Neisseria gonorrhoeae that confers serum bactericidal resistance. Infection and Immunity 55, 3017-3022.

NeUberger, M. S. \& RAJEWSKY, K. (1981). Activation of mouse complement by monoclonal mouse antibodies. European Journal of Immunology 11, 10121016.
Rice, P. A. \& Goldenberg, D. A. (1981). Clinical manifestations of disseminated infection caused by Neisseria gonorrhoeae and differences in bactericidal reactivity of infecting strains. Annals of Internal Medicine 95, 175-178.

Rice, P. A., Vayo, H. E., TaM, M. R. \& Blake, M. S. (1986). Immunoglobulin $G$ antibodies directed against protein III block killing of serum resistant Neisseria gonorrhoeae by immune serum. Journal of Experimental Medicine 164, 1735-1748.

SChoolnik, G. K., Buchanan, T. M. \& Holmes, K. K (1976). Gonococci causing disseminated infection are resistant to the bactericidal action of normal human serum. Journal of Clinical Investigation 58, 1163-1173.

VIRJI, M. \& HECKELS, J. E. (1985). Role of anti-pilus antibodies in host defence against gonococcal infection studied with monoclonal anti-pilus antibodies. Infection \& Immunity 49, 621-628.

VIRJI, M. \& HECKELS, J. E. (1986). The effect of protein II and pili on the interaction of Neisseria gonorrhoeae with human polymorphonuclear leucocytes. Journal of General Microbiology 132, 503-512.

VirJi, M., Heckels, J. E. \& Watt, P. J. (1983). Monoclonal antibodies to gonococcal pili : studies on antigenic determinants on pili from variants of strain P9. Journal of General Microbiology 129, 19651973.

VIRJ, M., ZaK, K. \& HeCKels, J. E. (1985). Use of monoclonal antibodies to detect common protein antigens present in outer membranes of Neisseria species. In The Pathogenic Neisseriae, pp. 276-280. Edited by G. K. Schoolnik. Washington, DC: American Society for Microbiology.

VIRJI, M., ZAK, K. \& Heckels, J. E. (1986). Monoclonal antibodies to gonococcal outer membrane protein IB: use in the investigation of the potential protective effect of antibodies directed against conserved and type-specific epitopes. Journal of General Microbiology 132, 1621-1629.

VIRJ, M., ZAK, K. \& Heckels, J. E. (1987a). Outer membrane protein III of Neisseria gonorrhoeae: variations in biological properties of antibodies directed against different epitopes. Journal of General Microbiology 133, 3393-3401.

VIRJ, M., FleTCHER, J. N., ZAK, K. \& HeCKels, J. E. $(1987 \mathrm{~b})$. The potential protective effect of monoclonal antibodies to gonococcal outer membrane protein IA. Journal of General Microbiology 133, 2639-2646.

ZaK, K., Diaz, J.-L., Jackson, D. \& Heckels, J. E. (1984). Antigenic variation during infection with Neisseria gonorrhoeae: detection of antibodies to surface proteins in sera of patients with gonorrheae. Journal of Infectious Diseases 149, 166-174. 